\title{
The Key Aspects of BRCA1 Interactome for Novel Breast Cancer Therapies
}

\section{Raji Sundararajan* and Ignacio G Camarillo}

Purdue University, West Lafayette, USA

*Corresponding Author: Raji Sundararajan, Purdue University, West Lafayette, USA
Received: November 30, 2021

Published: January 12, 2022

(C) All rights are reserved by $\mathbf{R a j i}$

Sundararajan and Ignacio G Camarillo.

\begin{abstract}
In Feb 2021, World Health Organization (WHO) announced that breast cancer overtook lung cancer as the \#1 cancer in the world. With over 2 million new cases and over 600,000 deaths in 2020, breast cancer is the most common cancer of women worldwide. About $10 \%$ of the breast cancer is familial (or hereditary), caused by mutations of Breast Cancer Susceptibility gene 1, commonly known as BRCA1. Located in chromosome 17, this gene has multiple functions, interactions, pathways and direct and indirect binding partners, contributing to the various hall marks of cancer, including cell cycle and other. It interacts with several genes and proteins and these interactions are studied using String diagrams. The goal is to obtain better insights of the various key aspects of these interactions and utilize them towards novel breast cancer therapies for familial breast cancer treatments.
\end{abstract}

Keywords: BRCA1; Breast Cancer; Familial; String Diagram; Gene Ontology; Pathways

\section{Introduction}

Cancer is a disease of somatic, chromosomal and gene mutations [1-10]. Inherited mutations in the BRCA1 (and BRCA2) genes are associated with hereditary breast and ovarian cancers, which is a disorder, marked by an increased lifetime risk of breast and ovarian cancers in women. Several other cancers have been associated with this, including pancreatic and prostate cancers, as well as male breast cancer [1-10]. The BRCA1 gene is conserved in chimpanzee, Rhesus monkey, dog, cow, mouse, rat, and chicken [9]. There are 293 organisms that have orthologs with human gene.

BRCA1 is a key gene in hereditary breast and ovarian cancers. BRCA1 mutation carriers are related to $70-80 \%$ of lifetime risk of hereditary breast cancer [1], while they are related to $50 \%$ of lifetime risk of ovarian cancer. They are also involved in the prostate cancer of Ashkenazi Jewish, with increased risk than normal people. Hereditary breast cancer accounts for only about $5-10 \%$ of all breast cancer [10], yet they have more propensity for tumor formation, and hence the occurrence of the other breast. Discovered in 1994 [11-13], BRCA1 encodes a 190 kD nuclear phospho- protein [9], that plays a major role in maintaining genomic stability. It also acts as a tumor suppressor. Located in chromosome 17q21 [11-13], it interacts closely with its counterpart BRCA2 gene as well as a large number of a variety of genes, such as sensor, mediator, and effector positions [1]. The BRCA1 gene contains 22 exons spanning about $110 \mathrm{~kb}$ of DNA, with 1863 amino acids [10]. The encoded protein combining with other tumor suppressors, DNA damage sensors, and signal transducers forms a large multi-subunit protein complex, known as BRCA1-associated genome surveillance complex (BASC) $[13,14]$. Table 1 shows the cumulative risk by age due to BRCA1 predisposing mutations [15].

\begin{tabular}{|l|c|}
\hline Age (years) & Cumulative Risk (\%) \\
\hline 30 & 3.2 \\
\hline 40 & 19.1 \\
\hline 50 & 50.8 \\
\hline 60 & 54.2 \\
\hline 70 & 85 \\
\hline
\end{tabular}

Table 1: The cumulative risk by age due to BRCA1 predisposing mutations [15]. 
Table 2 shows the various BRCA1 functions and the domains, along with the various direct and indirect binding partners [1]. Literature $[9,10,13]$ shows similar interactions with a number of other genes, which are studied in this research.

\begin{tabular}{|c|c|c|c|}
\hline Function & Domain & $\begin{array}{c}\text { Direct } \\
\text { Binding }\end{array}$ & $\begin{array}{l}\text { Indirect } \\
\text { Binding }\end{array}$ \\
\hline $\begin{array}{l}\text { Recruitment to } \\
\text { DNA damage } \\
\text { sites }\end{array}$ & BRCT & Abraxas & RAP80 \\
\hline $\begin{array}{l}\text { DNA end } \\
\text { resection }\end{array}$ & BRCT and RING? & CtlP & MRN complex \\
\hline $\begin{array}{l}\text { G2/M } \\
\text { checkpoint }\end{array}$ & $\begin{array}{c}\text { BRCT } \\
\text { BRCT } \\
\text { SCD (S1423 and } \\
\text { S1524 } \\
\text { Phosphorylation) }\end{array}$ & $\begin{array}{l}\text { Abraxas } \\
\text { CtlP } \\
\text { ATM }\end{array}$ & $\begin{array}{c}\text { RAP80 } \\
\text { MRN complex } \\
\text { MRN Complex }\end{array}$ \\
\hline $\begin{array}{l}\text { S-Phase } \\
\text { checkpoint }\end{array}$ & $\begin{array}{c}\text { SCD (S1387 } \\
\text { phosphorylation) } \\
\text { BRCT }\end{array}$ & $\begin{array}{c}\text { ATM } \\
\text { BRIP1 }\end{array}$ & $\begin{array}{c}\text { MRN complex } \\
\text { TOPBP1 }\end{array}$ \\
\hline $\begin{array}{l}\text { Repair during } \\
\text { DNA replication }\end{array}$ & BRCT & BRIP1 & TOPBP1 \\
\hline $\begin{array}{l}\text { Homologous } \\
\text { recombination }\end{array}$ & $\begin{array}{l}\text { Coiled coil and } \\
\text { S988 } \\
\text { phosphorylation }\end{array}$ & PALB2 & BRCA2 \\
\hline
\end{tabular}

Table 2: BRCA1 Functions and its domains and direct and indirect binding partners [1].

Note: BRCT-breast cancer carboxyl-terminal domain.

Figure 1 shows the Really Interesting New Gene (RING) Finger details [10]. There are currently 1600 mutations in a truncated BRCA1 protein.

The majority of deleterious BRCA1 mutations are large deletions, rearrangements, splice-site, frameshift, or nonsense changes that result in a truncated protein [16]. However, a handful of proven deleterious BRCA1 mutations are missense changes that occur in key conserved protein domains such as the Ring finger domain and the breast cancer $\mathrm{C}$-terminal domains. Figure 1 shows the Ring Finger details [10].

BRCA1 is a pleiotropic DNA damage response protein that operates in both check point activation and DNA repair [10]. BRCA1's role in tumorigenesis is related to a number of cellular processes. They include double strand DNA repair, transcriptional regulation
BRCA1

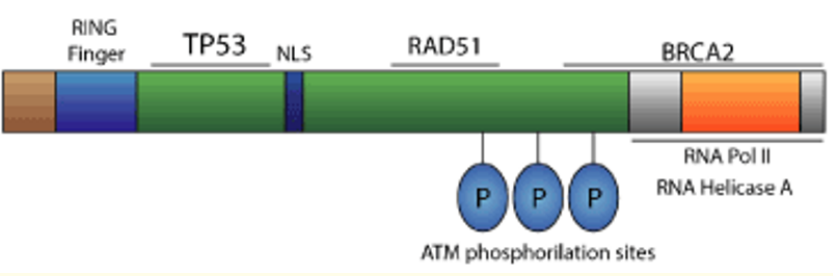

Figure 1: Ring Finger details [10].

of DNA repair-associated genes, and other. BRCA1 binds to BRCA2, TP53, and RAD51, in addition to other proteins associated with the cell cycle and DNA damage response genes. BRCA1 is involved in double-strand breaks (DSB) repair and play an important role in maintaining genomic stability $[17,18]$.

A partial list of various human triple negative breast cancer (TNBC) cell lines, along with the ethnicity of the patients from whom they were derived that have BRCA1, and their molecular classifications are shown in table 3 [19].

\begin{tabular}{|l|c|c|}
\hline Cell line & Ethnicity & Molecular classification \\
\hline HCC 38 & Caucasian & Basal B \\
\hline HCC 1143 & Caucasian & Basal A \\
\hline HCC 1937 & Caucasian & Basal A \\
\hline HCC 2157 & Black & Basal A \\
\hline MDA-MB-157 & Black & Basal B \\
\hline MDA-MB-231 & Caucasian & Basal B \\
\hline MDA-MB-468 & Black & Basal A \\
\hline
\end{tabular}

Table 3: A partial list of Human TNBC cell lines with BRCA1 [19].

BRCA1, a caretaker gene [20], is a tumor suppressor gene implicated in the predisposition to early onset breast and ovarian cancer [1-10]. Loss of the tumor suppressor BRCA1 function results in major chromosomal instability. As a tumor suppressor, BRCA1 exerts a pleiotropic effect, playing a role in the maintenance of genomic integrity. Several functions have also been ascribed to BRCA1, including double strand DNA break repair, participating in genome surveillance, transcription-coupled DNA repair, transcriptional regulation, chromatin remodeling, and ubiquitin ligation and cell cycle checkpoint arrests. In cells, loss of BRCA1 function leads to spontaneous chromosome breakage and sensitivity to DNA damage $[1-10,21]$. 
Although BRCA1 familial or hereditary breast cancer is only about 5 to $10 \%$ of all breast cancers, the incidence rate is higher for those family members [1-10]. It is of practical interest to explore this gene in detail, as it is involved in various other cancers also, such as prostate cancer and pancreatic cancer. It interacts with a large number of genes and proteins and these interactions are studies in this research.

\section{Methodology}

Google (MedLine, PubMed, and Google Scholar and images) was used to find various publications (1990 to 2021) that reported about BRCA1 and its various interacting genes, using terms, such as BRCA1, Notch. string-db.org [22] was used for generating all the string diarams and to study their interactions, the GO enrichment study, and the pathways.

\section{BRCA-1 Interactions}

\section{With ring finger genes}

Figure 2 shows the string interaction diagram [22] of BRCA1 with other Ring Finger genes, BRCA2, TP53, RAD51, and ATM, as shown in figure 1 [10]. It can be seen that there are more interactions (number of lines) between all of these genes, indicating the potency of BRCA1 to affect various cellular functions, along with these genes. Table 4 shows the top 5 GO enrichment terms for various Biological Processes (BPs), Molecular Functions (MFs), and Cellular Components (CCs). The various KEGG pathways include Homologous Recombination (HR), platinum drug resistance, p53 signaling pathway, breast cancer, cell cycle, apoptosis, and other.

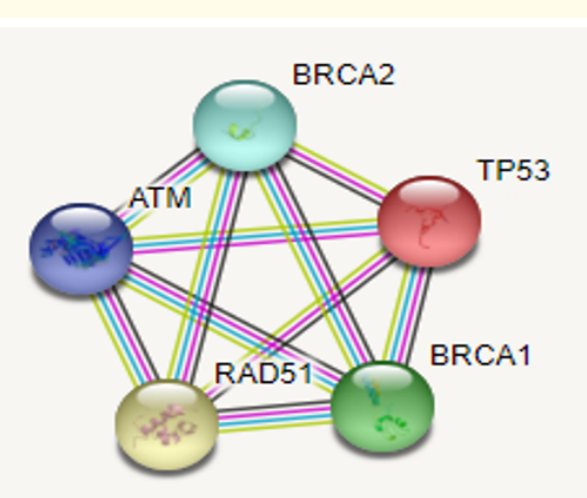

Figure 2: Interactions of BRCA1 with Ring Finger Genes
Biological Process

\begin{tabular}{c}
\hline Mitotic recombination-dependent replication fork processing \\
\hline Establishment of protein localization to telomere \\
\hline DNA damage response \\
\hline Signal transduction involved in G2 DNA damage checkpoint \\
\hline Telomere maintenance via recombination \\
\hline Molecular Function \\
\hline Identical protein binding \\
\hline Cellular Component \\
Lateral element \\
\hline Site of double strand break \\
\hline Microtubule organizing center \\
Microtubule cytoskeleton \\
Nuclear chromosome
\end{tabular}

Table 4: Top 5 GO Enrichment for the Ring Finger genes string diagram.

\section{With 23 other genes in [9]}

Figure 3 shows the string interaction diagram of BRCA1 with other 23 genes, as given in [9]. It can be seen that there are more interactions between BRCA1, BRCA2, and CDK4, compared to MAP3K. This indicates that BRCA1 is a key gene interacting a number of other key genes, related to various cancers.

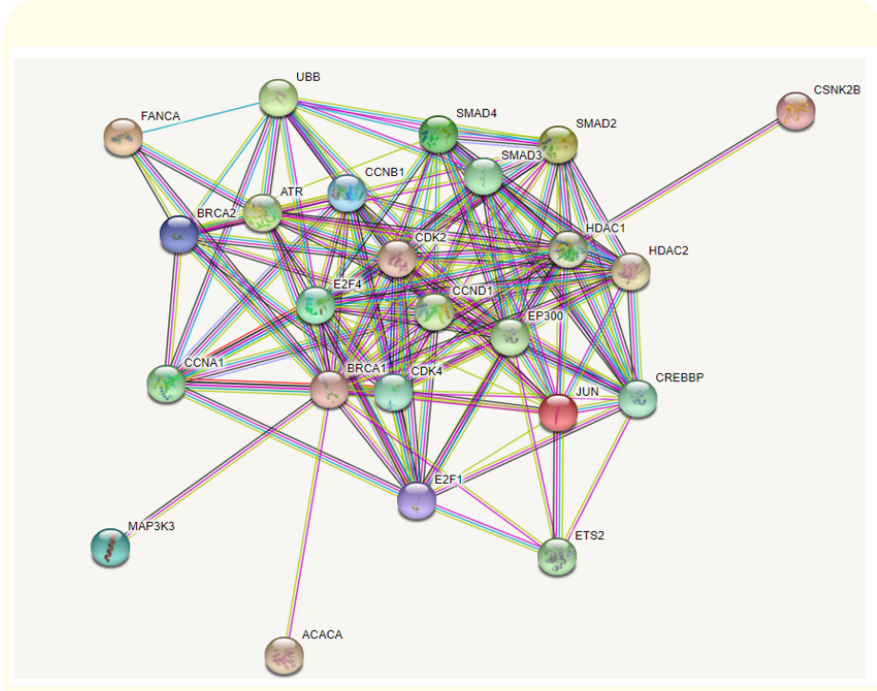

Figure 3: Interactions of BRCA1 with 23 other genes. 
Table 5 shows the top 5 GO enrichment of BPs, MFs, and CCs [22]. The various sub-cellular localizations include Homomeric SMAD protein complex, Cyclin A1-CDK2 complex, Cyclin D1-CDk4,
BRCA1-C complex, and Cyclin A2-CDK2 complex. The salient KEGG pathways include cell cycle, Notch signaling pathway, and other. Figure 4 shows the Notch signaling pathway [23].

NOTCH SIGNALING PATHWAY

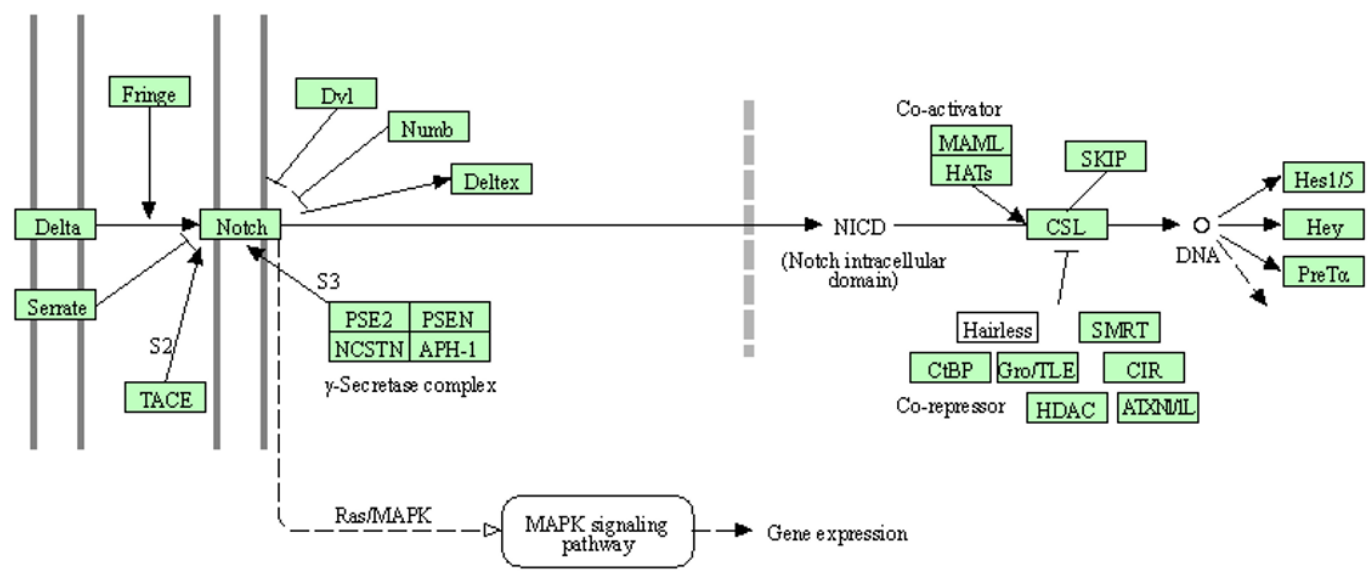

$043302 / 16 / 21$ (c) Kanehisa Laboratories

Figure 4: Notch Signalling pathway.

\begin{tabular}{|c|}
\hline Biological Process \\
\hline Fungiform papilla formation \\
\hline N-terminal peptidyl-lysine acetylation \\
\hline SMAD protein complex assembly \\
\hline Hair follicle placode formation \\
\hline Establishment of protein localization to telomere \\
\hline Molecular Function \\
\hline Primary miRNA binding \\
\hline NAD-dependent histone deacetylase activity (H3-K14 specific) \\
\hline I-SMAD binding \\
\hline Co-SMAD binding \\
\hline R-SMAD binding \\
\hline Cellular Component \\
\hline Cyclin A1-CDK2 complex \\
\hline Heteromeric SMAD protein complex \\
\hline Cyclin A2-CDK2 complex \\
\hline Activin responsive factor complex \\
\hline SMAD protein complex \\
\hline
\end{tabular}

Table 5: Top 5 GO Enrichment for the 23 gene string diagram.
The Notch signaling pathway is a highly conserved pathway in most animals, from sea urchins to humans, and plays a key role in controlling the differentiation of breast epithelial cells during normal development [24]. The Notch signaling is dysregulated in various cancers, including triple negative breast cancers, which contributes to oncogenesis, renewal of stem cells, angiogenesis, and chemoresistance [25].

Buckley., et al. [26] reported that BRCA1 is involved in the activation of Notch signaling with implications for anti-endocrine treatment of breast cancer. They demonstrated that inhibition of Notch signaling decreased sensitivity of Tamoxifen, the antiestrogen drug. Their findings suggest that BRCA1 transcriptional upregulation of Notch signaling is a key event in the normal differentiation process in breast tissue.

Notch pathway is involved in cell manipulation, differentiation, and apoptosis. Notch family is implicated in human breast cancer in different combinations [24]. The misregulated Notch ligand-receptor interaction in breast cancer could cause tumor growth initiation, progression, and maintenance by inducing aberrant tumor- 
igenesis, while determining vascular integrity. It is reported that there could be a direct involvement of the Notch pathway in normal mammary gland growth and breast carcinogenesis. Breast cancer clinical outcome was accompanied by high expression of Notch-1, $-3,-4$ pathways and Notch-2 was identified as a tumor suppressor in many studies. There were multiple studies indicating association of high levels of Notch signaling with different subtypes of breast cancer. Notch family members involved in different types of breast cancers could be utilized to provide novel therapies by considering the potential therapeutic use of monoclonal antibodies inhibiting the notch pathway.

With genes in the pathway of Genome protection

Figure 5 shows the interactions of BRCA1 with a number of other genes discussed in [1], while figure 6 shows the partial pathway of BRCA1 [21], that illustrates the same. The functions of these and other interacting proteins are given in table 6 [27].

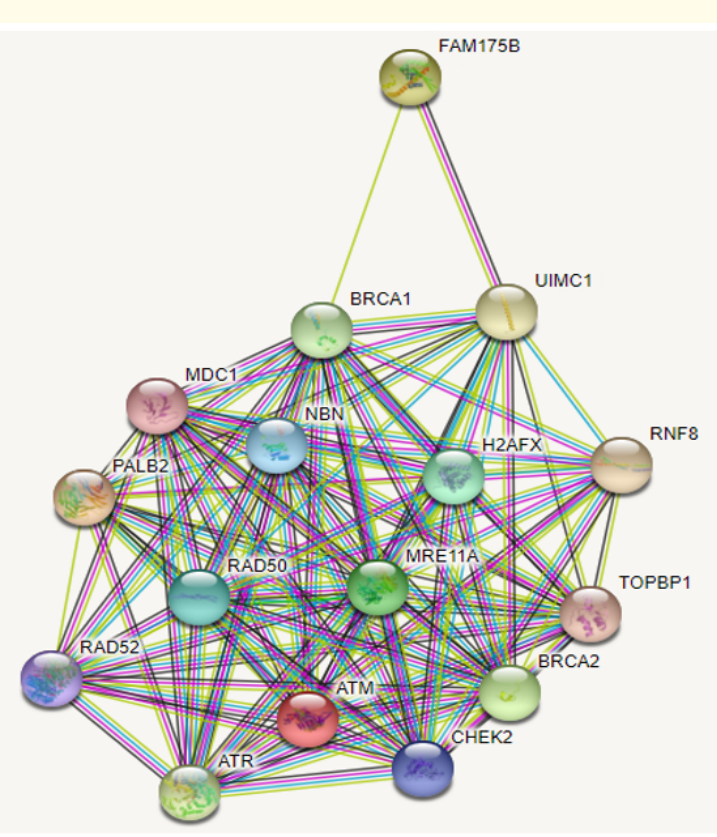

Figure 5: Interaction of BRCA1 with other genes in a common pathway of genome protection.

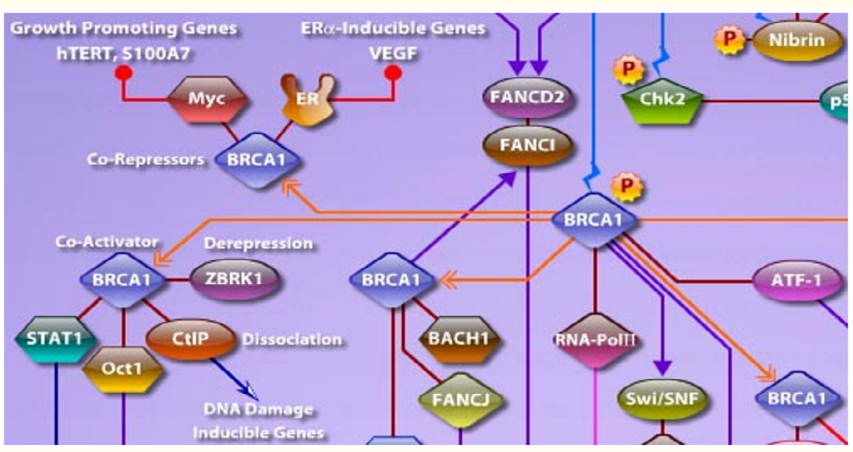

Figure 6: Partial BRCA1 Pathway [21].

\begin{tabular}{|c|c|}
\hline $\begin{array}{l}\text { BRCA1 interacting protein } \\
\text { or complex }\end{array}$ & Function of interacting protein \\
\hline RAD50 & DSB repair \\
\hline RAD51 & DSB repair \\
\hline BRCA2 & DSB repair \\
\hline $\begin{array}{l}\text { BASC (ATM, BLM, MSH2, } \\
\text { MSH6, MLH1, RCF }\end{array}$ & Mismatch pair \\
\hline ATP & Mismatch pair \\
\hline $\mathrm{H} 2 \mathrm{AX}$ & Signals DNA damage \\
\hline P53 & $\begin{array}{l}\text { Transcription factor; tumor sup- } \\
\text { pressor }\end{array}$ \\
\hline c-Myc & Transcription factor; oncogene \\
\hline ATF & Transcription factor \\
\hline STAT1 & $\begin{array}{l}\text { Signal transducer; transcrip- } \\
\text { tional activation }\end{array}$ \\
\hline $\mathrm{E} 2 \mathrm{~F}$ & $\begin{array}{c}\text { Transcription factor; cell cycle } \\
\text { regulator }\end{array}$ \\
\hline Estrogen receptor & $\begin{array}{l}\text { Ligand responsive transcription } \\
\text { factor }\end{array}$ \\
\hline Androgen receptor & $\begin{array}{l}\text { Ligand responsive transcription } \\
\text { factor }\end{array}$ \\
\hline CtlP & $\begin{array}{c}\text { Binds CtBP; transcriptional; co- } \\
\text { repressor }\end{array}$ \\
\hline $\begin{array}{l}\text { Centrosome (p53, pRB, } \\
\text { Nm23) }\end{array}$ & Chromosome segregation \\
\hline BRAP2 & Cytoplasmic retention \\
\hline BARD1 & Ubiquitin ligase \\
\hline PALB2 & DSB repair \\
\hline
\end{tabular}

Table 6: List of various BRCA1 interacting proteins or complexes and their functions [27]. 
This set of genes also have the same KEGG pathways as in figure 2. Table 7 gives the top 5 GO terms of BPs, MFs, and CCs.

\begin{tabular}{|c|}
\hline Biological Process \\
\hline Positive regulation of telomerase catalytic core complex \\
\hline Establishment of protein-containing complex \\
\hline Establishment of RNA localization to telomere \\
\hline Telomeric 3 overhang formation \\
\hline Establishment of protein localization to telomere \\
\hline Molecular Function \\
\hline Damaged DNA binding \\
\hline Protein c-terminus binding \\
\hline Identical protein binding \\
\hline DNA binding \\
\hline Protein binding \\
\hline Cellular Component \\
\hline Mre11 complex \\
\hline BRCA1-A complex \\
\hline Male germ cell nucleus \\
\hline Lateral element \\
\hline Site of double-strand-break \\
\hline
\end{tabular}

Table 7: Top 5 GO Enrichment for the above HSP string diagram.

Detection of DNA double-strand breaks involves sensor proteins of the MRN complex [8,13], composed of MRE11A, RAD50 and NBN (NBS1). Binding of the MRN complex to DNA DSBs activates ATM-dependent DNA damage signaling cascade, by promoting KAT5 (Tip60) mediated acetylation of ATM and subsequent ATM autophosphorylation. Activated ATM triggers and coordinates recruitment of repair proteins to DNA DSBs [3-10].

BRCA1 colocalizes in nuclear foci with RAD51, thereby implicating B1 in homologous recombination (HR) during meiosis and repair of DSBs [28]. These DSBs arise following exposure to ionizing radiation or free radicals and following DNA damage during replication at the site of replication fork. It is believed that DSBs are the main cause of genomic instability and chromosomal rearrangements that are hallmarks of cancer.

BRCA1-ATF is directly involved with homologous recombination (HR)-mediated repair of DNA double strand breaks [1]. It binds to DSBs through its association with the abraxas-RAP80 macro-com- plex. BRCA1 is involved in processing DSBs through its interactions with CtlP and the MRN complex. BRCA1 is also required for RAD51 recruitment to the sites of DNA damage through its interactions with PALB2 and BRCA2.

BRCA1 interacts directly with estrogen receptor- $\alpha$ (ER- $\alpha$ ), and Androgen receptor (AR); it represses ER- $\alpha$ and stimulates AR activity [12]. This and other findings correlate that BRCA1 mutations enhance the risk for several ER-positive cancers, including breast, uterine, and cervical and AR-related cancers, such as prostate cancer. In addition to stimulating tumor suppressor and growth inhibitor pathways, BRCA1 can inhibit oncogene activity. It binds to c-Myc oncogene, which is amplified or overexpressed in many cancers and inhibit its transcriptional and transformation activities.

All these interactions illustrate the different functions of the BRCA1 protein and their significance regarding developing different treatment options for patients who are BRCA1 mutant carriers or sporadic breast cancer patients with loss of BRCA1 expression in their tumors [3]. Similar results were also obtained with the BASC genes.

\section{With genes in BASC super complex}

BRCA1-associated genome surveillance complex (BASC) is a large complex of group of proteins that is associated with BRCA1 $[13,14]$. These include tumor suppressor and DNA damage repair proteins, such as MSH2, MSH6, and other. A string diagram of their interactions is shown in figure 7. The various KEGG pathways include non-homologous end joining, homologous recombination, mismatch pair, platinum drug resistance, and cellular senescence. Figure 8 shows the Homologous Recombination pathway [29]. Table 8 shows the top 5 GO enrichment terms.

The BASC super complex also contains PCNA, which is needed for DNA synthesis [13]. They all function in DNA metabolism and repair. Several of these also participate in cell cycle checkpoint functions to halt cell cycle progression when there is a damaged DNA.

HR is a critical pathway for DNA repair [28]. DSBs can be repaired using HR pathway. HR utilizes an undamaged sister chromatid as a repair template [30] to restore any damaged/lost sequence information at the DSB site. Since it requires a sister template to repair, HR pathways is only available during S/G2 phases of the cell cycle. 


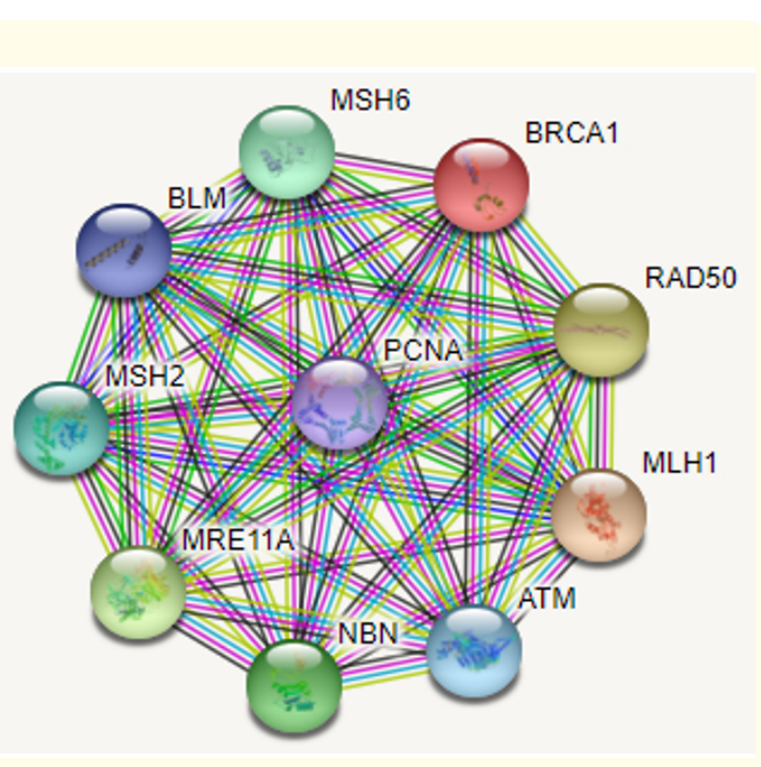

Figure 7: BASC complex protein interactions.

\begin{tabular}{|c|}
\hline Biological Process \\
\hline Telomeric 3overhang formation \\
\hline Regulation of mitotic recombination \\
\hline Positive regulation of isotype switching to iga isotypes \\
\hline Negative regulation of telomere capping \\
\hline
\end{tabular}

\begin{tabular}{|c|}
\hline Positive regulation of helicase activity \\
\hline Molecular Function \\
\hline Guanine/thymine mis pair binding \\
\hline Mismatched DNA binding \\
\hline G-quadruplex DNA binding \\
\hline Damaged DNA binding \\
\hline DNA secondary structure binding \\
\hline Cellular Component \\
\hline Mre11 complex \\
\hline MutSalpha complex \\
\hline Mismatch repair complex \\
\hline Lateral element \\
\hline DNA repair complex \\
\hline Mubcellular localization compartments \\
\hline MutSbeta complex \\
\hline MutSalpha complex \\
\hline MutLalpha complex \\
\hline Mre11 complex \\
\hline MutS complex \\
\hline
\end{tabular}

Table 8: Top 5 GO Enrichment for the BASC Proteins string diagram.
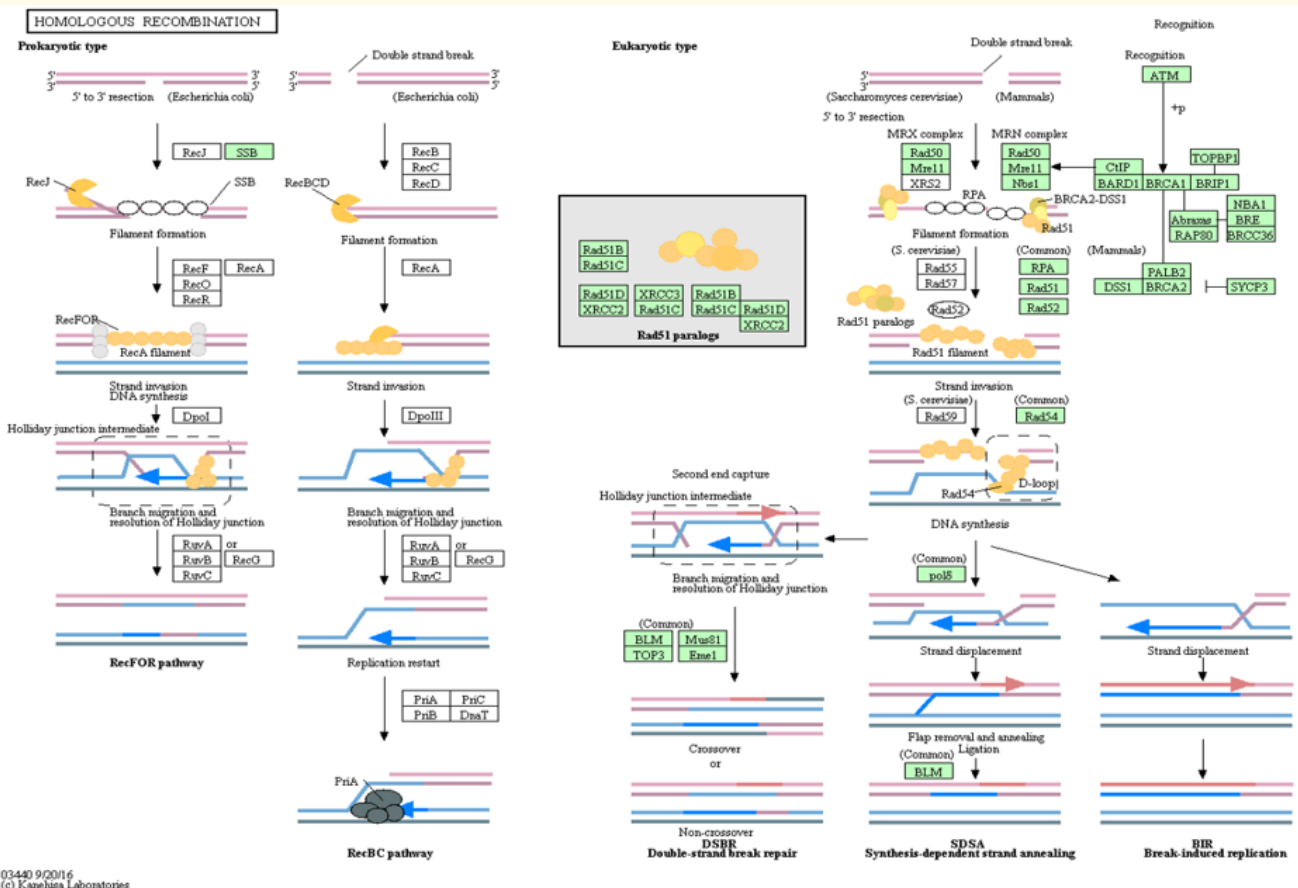

Figure 8: Homologous Recombination pathway, illustrating the various protein interactions. 


\section{PARP inhibitors for BRCA1 breast cancer}

In addition to surgery, and chemotherapy using Taxanes and platinum-based compounds, use of Poly (ADP-ribose) polymerase (PARP) inhibitors have received major attention as therapeutic agents for the treatment of breast cancers with or without mutations in BRCA1, due to its DNA repair mechanisms $[10,28]$. Thus, it can be effectively used for TNBC, with possible BRCA1 mutation as, BRCA1 mutation could cause TNBC, with basal-like subset of breast cancers $[2,31]$, which lack the conventional receptors that many chemo drugs attack. Veliparib, a PARP agent is used as a $2^{\text {nd }}$ line of treatment along with platinum compounds. The efficacy of Veliparib, as an anti-cancer drug was studied in our research [32], using MDA-MB-231, human triple negative breast cancer cells. A concentration of 1 to $500 \mu \mathrm{M}$ was used for this purpose. Figure 9 shows the viability results at various doses.

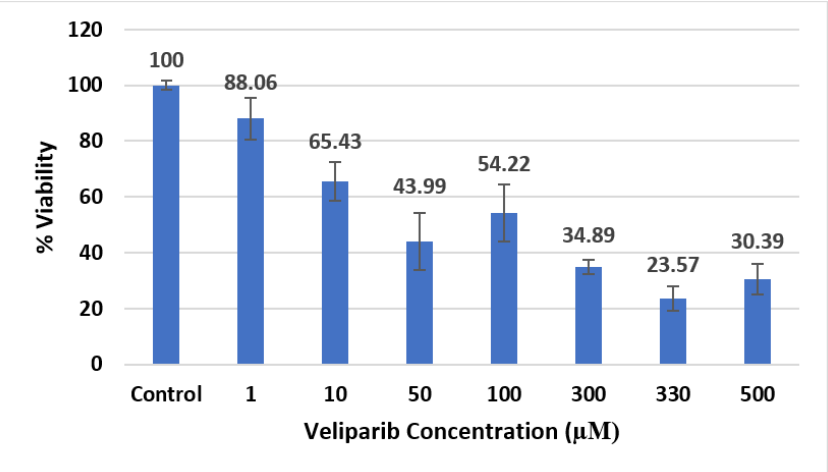

Figure 9: Viability of MDA-MB-231 cells at various Veliparib doses.

With control normalized to $100 \%$ viability, the viabilities range from $88 \%$ for $1 \mu \mathrm{M}$ to $65.43 \%$ at $10 \mu \mathrm{M}$. The viability was reduced to $43.99 \%$ at $50 \mu \mathrm{M}$. However, it increased to $54.22 \%$ at $100 \mu \mathrm{M}$ and reduced to 34.89 for $300 \mu \mathrm{M}$. The lowest viability of $23.57 \%$ was obtained for $330 \mu \mathrm{M}$. An increase in viability is observed with increase in dosage of Veliparib with $30.39 \%$ viability for $500 \mu \mathrm{M}$. This increase in viability could be attributed to the saturation of the drug, which correlates with the results obtained in another study by Jung-Min Lee., et al. [33], where they report the $11 \%$ of cell kill at $50 \mu \mathrm{M}$ concentration of Veliparib [33].

\section{Conclusion}

Conserved from chimpanzee, Rhesus monkey, dog, cow, mouse, rat, and chicken, and discovered in 1994, BRCA1, a caretaker gene, is very important and versatile molecule that links, binds, and in- teracts with a number of other proteins related to DNA damage. These were illustrated by the numerous interactions with a number of other proteins, using various string diagrams, showing its strong, intermediate, and weak interactions with these.

Based on its associations and physical interactions with other proteins, BRCA1 has been implicated in a wide array of cellular functions, including cell cycle regulation, DNA damage response, maintenance of genomic stability, transcription regulation, replication, and recombination as well as higher chromatin hierarchical control. Identification of BRCA1 has led to major changes in the treatment of women with inherited breast and ovarian cancers. Nevertheless, it is unclear which loss of function contributes to cancer initiation and progression.

The Notch signaling pathway, with major participation and playing multiple roles in breast cancer progression could be a critical part of BRCA1 therapy, inhibiting which could provide innovative therapeutic options.

PARP inhibitors are other potential candidates to treat BRCA-1, triple negative and other breast cancers. More research is needed to utilize the great discovery of the BRCA1, for the benefit of breast cancer patients.

\section{Acknowledgements}

None.

\section{Conflict of Interest}

None.

\section{Bibliography}

1. R Roy., et al. "BRCA1 and BRCA2: different roles in a common pathway of genome protection". Nature Reviews-Cancer (2012): 12.

2. Talhouset., et al. "Clinical outcome of breast cancer in carriers of BRCA1 and BRCA2 mutations according to molecular types". Scientific Reports 10 (2020): 7073.

3. RI Yarden and MZ Papa. "BRCA1 at the crossroad of multiple cellular pathways: approaches for therapeutic interventions". Molecular Cancer Therapeutics 5.6 (2006).

4. Easton., et al. "Breast and Ovarian cancer incidence in BRCA1mutation". American Journal of Human Genetics (1995): 56.

5. Zhang., et al. "Comprehensive analysis of BRCA1 and BRCA2 germline mutations in a large cohort of 5931 Chinese women with breast cancer". Breast Cancer Research and Treatment (2016): 158. 
6. Easton., et al. "Breast and ovarian cancer incidence in BRCA1 mutation". American Journal of Human Genetics 56 (1995): 265-271.

7. Rennert., et al. "Clinical outcomes of breast cancer in carriers of BRCA1 and bRCA2 mutations". The New England Journal of Medicine 357.2 (2007).

8. Turnbull C and Rahman R. "Genetic predisposition to breast cancer: Past, present, and Future". Annual Review of Genomics and Human Genetics 9 (2008): 321-345.

9. https://www.ncbi.nlm.gov/gene/672.

10. Godet I and Gilkes DM. "BRCA1 and BRCA2 mutations and treatment strategies for breast cancer". Integrative Cancer Science and Therapeutics (2017).

11. Miki., et al. "A strong candidate for the $17 \mathrm{q}$-linked breast and ovarian cancer susceptibility gene BRCA1". Science 266 (1994): 66-71.

12. Rosen EM., et al. "BRCA1 regulation of transcription". Cancer Letters 236 (2006): 175-185.

13. Wang., et al. "BASC, a super complex of BRCA1-associated proteins involved in the recognition and repair of aberrant DNA structures". Genes and Development 14 (2000): 927-939.

14. Rouillard AD., et al. "The harmonizome: a collection of processed datasets gathered to serve and mine knowledge about genes and proteins". Database (Oxford) (2006).

15. http://www.au-kbc.org/research_areas/bio/projects/bcinfo/ gen/bcgenetics1.html.

16. Sweet., et al. "Characterization of BRCA1 Ring Finger variants of uncertain significance". Breast Cancer Research Treatment 119.3 (2010): 737-743.

17. Duncan JA., et al. "BRCA1 and BRCA2 proteins: roles in health and disease". Molecular Pathology: MP 51.5 (1998): 237-247.

18. Gudmundsdottir $\mathrm{K}$ and Ashworth A. "The roles of BRCA1 and BRCA2 and associated proteins in the maintenance of genomic stability". Oncogene 25.43 (2006): 5864-5874.

19. Chavez KJ., et al. "Triple negative breast cancer cell lines: one tool in the search for better treatment of triple negative breast cancer". Breast Disease 32.1-2 (201): 35-48.

20. Deininger P. "Genetic instability in cancer: Caretaker and Gatekeeper genes”. The Ochsner Journal 1.4 (1999): 206-209.

21. https://www.abeomics.com/brca1-pathway.
22. string-db.org.

23. https://www.kegg.jp/kegg-bin/show_pathway?hsa04330.

24. Kontomanolis., et al. "The Notch pathway in breast cancer progression". The Scientific World Journal (2018).

25. Krishna., et al. "Notch signaling in Breast cancer: From pathway analysis to therapy". Cancer Letter 461 (2019): 123-131.

26. Buckley., et al. "BRCA1 is a key regulator of breast differentiation through activation of Notch signaling with implications for anti-endocrine treatment of breast cancers". Nucleic Acids Research 41.18 (2013).

27. L Fitzgerald. "The roles of P53, BRCA1, and PTEN in hereditary cancers" (2021).

28. Murthy P and Muggia F. "Women's cancers: how the discovery of BRCA1 is driving current concepts of cancer biology and therapeutics". Ecancer 13 (2019): 904.

29. https://www.kegg.jp/kegg-bin/show_pathway?hsa03440.

30. Savage KI and Harkin DP. "BRCA1, a 'complex' protein involved in the maintenance of genomic stability". FEBS Journal 282 (2015): 630-646.

31. Dai X., et al. "Breast cancer cell line classification and its relevance with breast tumor subtyping". Journal of Cancer 8.16 (2017): 3131-3141.

32. Mittal L., et al. "Electrical pulse-mediated Veliparib for the treatment of triple negative breast cancer: An in vitro model study". International Journal on Current Research and Academic Review 5.3 (2017): 53-64.

33. Lee J., et al. "Abstract A249: Navitoclax and veliparib yield cytotoxicity with lower doses than used for single agents in women's cancers". Molecular Cancer Therapeutics 12.11 (2013).

\section{Assets from publication with us}

- Prompt Acknowledgement after receiving the article

- Thorough Double blinded peer review

- Rapid Publication

- Issue of Publication Certificate

- High visibility of your Published work

Website: www.actascientific.com/

Submit Article: www.actascientific.com/submission.php

Email us: editor@actascientific.com

Contact us: +919182824667 